\title{
Влияние ферментации концентрированной молочной сыворотки на выделение органических кислот при электрообработке
}

\author{
И. И. Вуткарева \\ Институт прикладной физики, \\ 2. Кишинев, MD-2028, Республика Молдова, е-таil: irinavutkareva@yahoo.com \\ Поступила в редакцию 28.11.2019 \\ После доработки 14.11.2020 \\ Принята к публикации 23.11.2020
}

\begin{abstract}
Исследована проблема переработки вторичных ресурсов молочной промышленности молочной сыворотки, вырабатываемой в больших объемах при производстве творога и сыра. Приведены результаты изучения процесса выделения органических соединений при фракционировании молочной сыворотки перегонкой под вакуумом. Выявлено, что целесообразно обрабатывать концентрированную сыворотку. Обработка молочной сыворотки с помощью фракционной перегонки под вакуумом позволяет отделить органические кислоты требуемой чистоты и необходимой концентрации. Рассмотрено направление рентабельной переработки молочной сыворотки, которое сочетает концентрацию сыворотки с помощью фракционной перегонки и последующую электрообработку. Этот процесс позволяет разделить органические вещества сыворотки и направить дальнейшее концентрирование получаемых препаратов в сторону образования отдельных органических соединений.
\end{abstract}

Ключевые слова: молочная сыворотка, электролиз, фракционная перегонка

УдК 544.642

https://doi.org/10.52577/eom.2021.57.2.48

\section{ВВЕДЕНИЕ}

Промышленная переработка молочной сыворотки в настоящее время осуществляется по трем основным направлениям: комплексное использование всего сухого остатка; извлечение и глубокое фракционирование отдельных наиболее ценных компонентов; направленная химическая, ферментативная или биологическая трансформация отдельных компонентов с целью получения промышленно важных производных. Полное использование всего сухого остатка молочной сыворотки возможно при производстве напитков, сгущенных и сухих продуктов. Сгущение и сушка позволяют сгладить сезонность переработки молочной сыворотки, сократить затраты на транспортировку сывороточных концентратов [1].

В молочном производстве огромное количество вторичного сырья - молочной сыворотки - собирается в резервуарах и в случае ее невостребованности выливается в окружающую среду. Соответственно наблюдаются различия в физико-химических и микробиологических показателях сыворотки на различных этапах производства. Это, вероятно, вызвано различной продолжительностью хранения сыворотки до момента начала сгущения, а также использованием сыворотки, собранной при выработке различных видов продукции - творожной массы или сыра. Об этом свидетельствует факт высокой корреляции между величинами активной кислотности и массовой доли лактозы. Коэффициент корреляции составил 0,89 [2].

Использование сыворотки сдерживается рядом факторов. В частности, это проблемы с хранением и транспортировкой сыворотки на большие расстояния из-за удаленности предприятий; недоступность крупных централизованных предприятий, специализирующихся на переработке сыворотки; отсутствие массового производства продуктов на основе молочной сыворотки; недостаток должного контроля и санкций со стороны экологической службы за сброс сыворотки в сточные воды; использование на предприятиях устаревшего оборудования (сушильные установки), что связано с повышением расхода энергоносителей и соответственно получением неконкурентоспособной продукции [3].

Цель работы - создание устройства для экономически эффективной переработки молочной сыворотки и аналитические исследования влияния режимов его работы на процесс концентрирования.

\section{ЭКСПЕРИМЕНТАЛЬНАЯ ЧАСТЬ}

Объектом исследований являлась подсгущенная творожная сыворотка с массовой долей сухих веществ $9 ; 11 ; 12 ; 13 \%$. В ходе исследований контролировались физико-химические 
показатели в процессе концентрирования сыворотки в вакуум-выпарном аппарате эжекторного типа с фракционным разделением отгона и при последующей электролизной обработке. Результаты показали, что с повышением температуры от $(15 \pm 1,0)^{\circ} \mathrm{C}$ до $(30,0 \pm 1,0)^{\circ} \mathrm{C}$ наблюдается развитие термофильной микрофлоры в образцах натуральной творожной сыворотки и дрожжей как в образцах натуральной сыворотки, так и в образцах подсгущенной сыворотки [4]. Увеличивая концентрацию пищевых сред, можно добиться такого значения осмотического давления, при котором создаются неблагоприятные условия для развития микроорганизмов [5]. Тепловую обработку (пастеризацию) молочной сыворотки проводят при температуре $(72 \pm 2)^{\circ} \mathrm{C}$ с выдержкой 15-20 с и последующим охлаждением до температуры $(8 \pm 2)^{\circ} \mathrm{C}$ [6]. Если до электролиза сыворотку подвергать обработке в вакуум-выпарном аппарате, то пастеризацию сыворотки можно исключить.

Результаты проведенных исследований позволили обосновать выбор оптимальных режимов концентрирования и процесса электролизной обработки творожной сыворотки, при котором возрастают производительность и качество получаемых препаратов.

Произведен отбор молочной сыворотки из резервуара на Кишиневском молокозаводе, где она хранилась несколько дней с целью ее дальнейшего подсгущения и использования в производстве пищевых кислот. Для сравнения отбирали творожную сыворотку непосредственно на линии производства творожного продукта.

Для концентрирования использовали вакуумвыпарной аппарат эжекторного типа с фракционным удалением отгона. Отгон - легкокипящие фракции ацетальдегида и уксусной кислоты.

Стенд для концентрации сыворотки был разработан в соответствии со следующими требованиями: испарение 50\% свободной влаги при требуемой температуре испарения до определенного объема сгущенной сыворотки. Практически сыворотка сгущалась до содержания сухих веществ 9; $11 ; 12 ; 13 \%$.

Характерными параметрами, которые определяют процесс концентрации путем испарения свободной влаги из сыворотки, являются температура и продолжительность обработки [7]. Для сохранения нативных свойств молочной сыворотки желательно поддерживать максимальную температуру конденсации $45^{\circ} \mathrm{C}$ [8]. Понижение температуры термического агента при вакуумировании сыворотки $\left(45^{\circ} \mathrm{C}\right)$ способствует снижению потерь кислоты [9]. В этом случае низкая температура в процессе электрообработки сохраняется дольше.

Электрофизическую обработку подсгущенной молочной сыворотки проводили в диафрагменном электролизере при постоянном напряжении на протяжении всего процесса. В качестве диафрагмы использовалась мембрана МА-40.

В электролизере реакции протекают одновременно с выделением (разделением) их продуктов на полупроницаемых мембранах [10]. Они выгодно отличаются как от систем с иммобилизованными (на различных носителях) катализаторами, ферментами и микроорганизмами, так и от биореакторов для глубинного культивирования микроорганизмов и гидролиза (ферментолиза, автолиза) высокомолекулярных соединений, дрожжей и других микроорганизмов. От первых - тем, что ферменты (катализаторы, микроорганизмы-продуценты) находятся в растворе, и биохимические реакции не лимитируются медленно протекающей диффузией, а от вторых - возможностью смещения биосинтеза или гидролиза в сторону образования целевых продуктов [11]. Это происходит в соответствии с одним из основных законов химической термодинамики (принципом смещения равновесия Ле Шателье-Брауна) - удаление продукта из зоны реакции сдвигает равновесие в сторону его образования [11].

Все эти условия создают предпосылки к:

- увеличению концентрации продуктов биосинтеза и степени биоконверсии сырья теоретически до 100\%;

- уменьшению объемов устройства за счет увеличения скорости биокатализа путем постоянного и непрерывного обновления питательной среды и вывода целевых продуктов и метаболитов;

- сокращению расхода ферментов (заквасок) за счет многократного их использования.

Прошедший через мембрану раствор практически не содержит концентрируемые в объеме устройства ферменты, микроорганизмы, белки, которые обычно практически полностью задерживаются полупроницаемой мембраной.

Как показали проведенные в лаборатории мембранных технологий Всероссийского НИИ пищевой биотехнологии теоретические и экспериментальные исследования [11], в пищевой биотехнологии могут применяться мембраны только в разбавленных средах (сыворотка) и при использовании в качестве продуцентов молочнокислых, уксуснокислых бактерий. Поэтому сыворотка подсгущалась до содержания сухих веществ $13 \%$. 


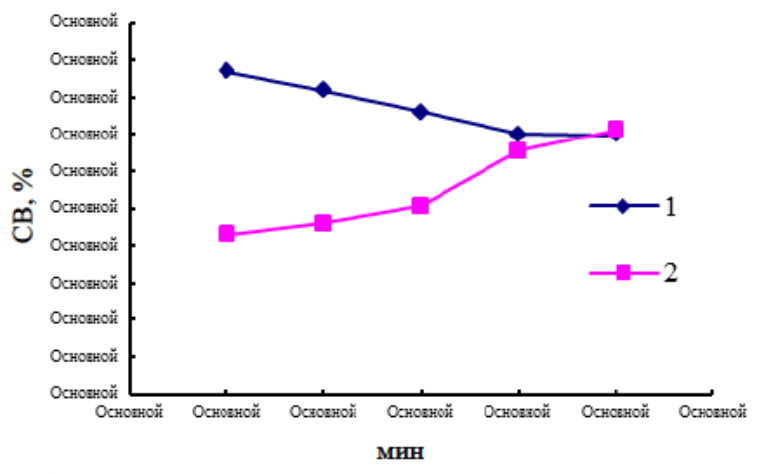

(a)

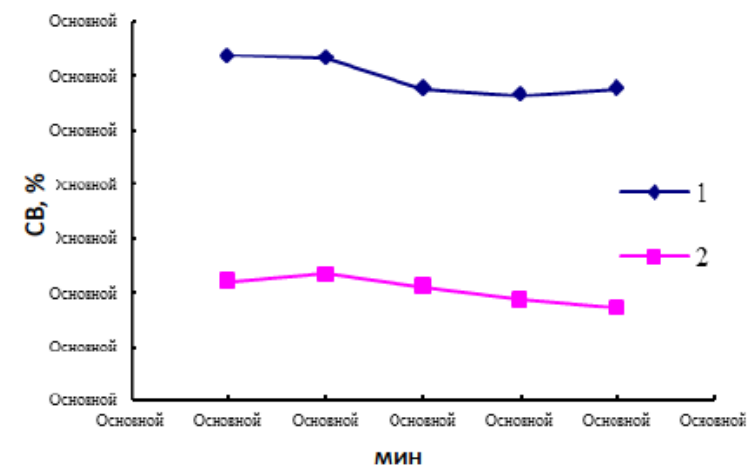

(б)

Рис. 1. Зависимость изменения содержания сухих веществ в ячейках электролизера при расстоянии между электродами 1 см (a) и 2 см (б): 1 - катодная камера; 2 - анодная камера.

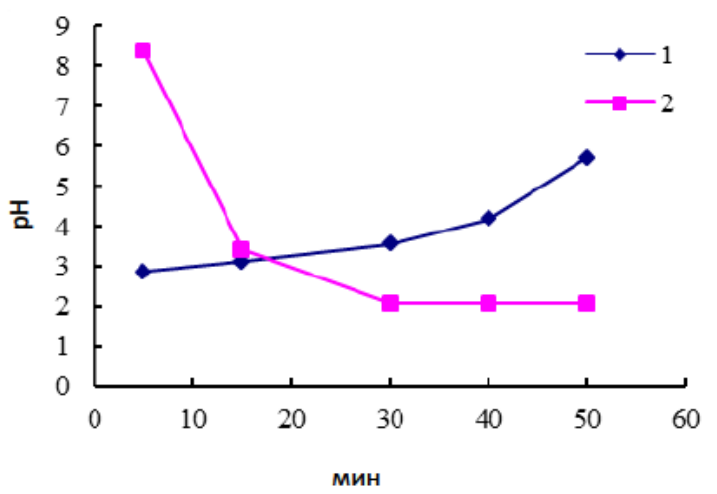

(a)

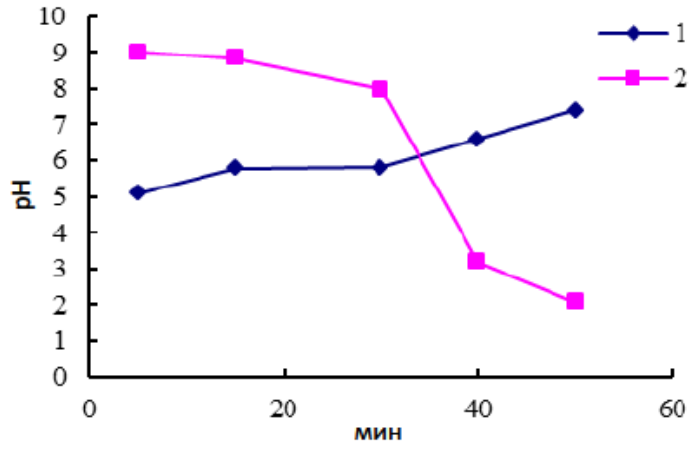

(б)

Рис. 2. Зависимость активной кислотности от степени ферментации сыворотки: (а) - ферментированная сыворотка; (б) - свежая сыворотка ( 1 - катодная камера; 2 - анодная камера).

С целью увеличения содержания кислоты в обрабатываемом растворе молочной сыворотки необходима ферментация соответствующими штаммами молочнокислых бактерий [4]. Для сбраживания лактозы молочной сыворотки в качестве молочнокислых бактерий использовали L. Acidophilus. Ферментированная сыворотка поступала в катодную камеру электролизера.

При увеличении температуры концентрируемой молочной (творожной) сыворотки производительность мембраны по фильтрату возрастает. Это связано с уменьшением вязкости сыворотки и соответственно со снижением плотности слоя задерживаемых веществ на мембране, то есть сопротивление слоя с увеличением температуры падает [10]. При температуре выше $60^{\circ} \mathrm{C}$ происходит денатурация сывороточных белков. Поэтому эксперименты при данных температурах не проводились.

Исследования осуществлялись в электролизере с плоскими вертикальными электродами графитовым анодом и катодом из нержавеющей стали. Анодная камера заполнялась слабым раствором электролита (слабый раствор $\mathrm{NaHCO}_{3}$ ). Процесс электролиза длился менее часа при постоянном напряжении 29 В.

\section{РЕЗУЛЬТАТЫ И ИХ ОБСУЖДЕНИЕ}

Процесс электролиза определяется плотностью тока, зависимой от расстояния между электродами. Начальная плотность тока $10 \mathrm{MA} / \mathrm{cm}^{2}$. Расстояние составляет от 1 до $2 \mathrm{~cm}$. При расстоянии 1 см концентрация раствора в анодной камере (АК) достигает $7-8 \%$ по сухому веществу, при 2 см концентрация сухих веществ в кислотном концентрате составляет 4\% (рис. 1).

В первом случае в катодной камере оставалось 7\% сухого вещества. При большем расстоянии между электродами содержание сухих веществ в катодной камере составляло $11,5 \%$ (начальное содержание сухих веществ $13 \%$ в исходной концентрации).

Большое значение имеет сбраживание сыворотки. В случае ферментированной сыворотки происходит накопление сухого вещества в камере, в случае неферментированной миграция сухого вещества происходит в первые 10 минут активирования процесса.

Степень сбраживания сыворотки влияет на изменение активной кислотности в катодной и анодной камерах в процессе электролиза (рис. 2).

В случае с ферментированной сывороткой активная кислотность в катодной камере находится на уровне 4-5-6 в кислой и слабокислой 
Таблица 1. Свойства концентрата в зависимости от свежести сыворотки

\begin{tabular}{|l|c|c|c|}
\hline Показатели & $\begin{array}{c}\text { Переброженная } \\
\text { сыворотка }\end{array}$ & $\begin{array}{c}\text { Ферментированная } \\
\text { сыворотка }\end{array}$ & Свежая сыворотка \\
\hline Сухие вещества, \% & 8,09 & 9,68 & 10,90 \\
\hline Плотность & 32,05 & 38,31 & 43,25 \\
\hline Лактоза, \% & 4,43 & 5,30 & 5,96 \\
\hline Соли, \% & 0,67 & 0,8 & 3,98 \\
\hline Белки, \% & 2,95 & 3,54 & 4,45 \\
\hline рН & 3,65 & 3,81 & 7,37 \\
\hline Проводимость, $\mathrm{mS} / \mathrm{cm}$ & 7,22 & 7,36 & \\
\hline
\end{tabular}

Таблица 2. Свойства отгона в зависимости от свежести сыворотки

\begin{tabular}{|l|c|c|c|c|c|c|}
\hline \multirow{2}{*}{ Показатели } & \multicolumn{2}{|c|}{$\begin{array}{c}\text { Переброженная } \\
\text { сыворотка }\end{array}$} & \multicolumn{2}{|c|}{$\begin{array}{c}\text { Ферментированная } \\
\text { сыворотка }\end{array}$} & \multicolumn{2}{c|}{ Свежая сыворотка } \\
\cline { 2 - 7 } & 1 отгон $^{*}$ & 2 отгон & 1 отгон & 2 отгон & 1 отгон & 2 отгон \\
\hline Сухие вещества, \% & 3,15 & 1,96 & 3,89 & 0,3 & 0,13 & 0,00 \\
\hline Плотность & 12,39 & 7,84 & 15,22 & 1,31 & 0,85 & 0,00 \\
\hline Лактоза, \% & 1,73 & 1,06 & 2,14 & 0,016 & 0,06 & 0,00 \\
\hline Соли, \% & 0,26 & 0,16 & 0,32 & 0,02 & 0,00 & 0,00 \\
\hline Белки, \% & 1,15 & 0,71 & 1,43 & 0,01 & 0,04 & 0,00 \\
\hline рН & 3,67 & 3,72 & 3,69 & 3,75 & 3,16 & 3,6 \\
\hline Проводимость, $\mathrm{mS} / \mathrm{cm}$ & 2,75 & 2,14 & 3,58 & 2,14 & 2,30 & 2,39 \\
\hline
\end{tabular}

* Отгоны содержат так называемый уксус брожения.

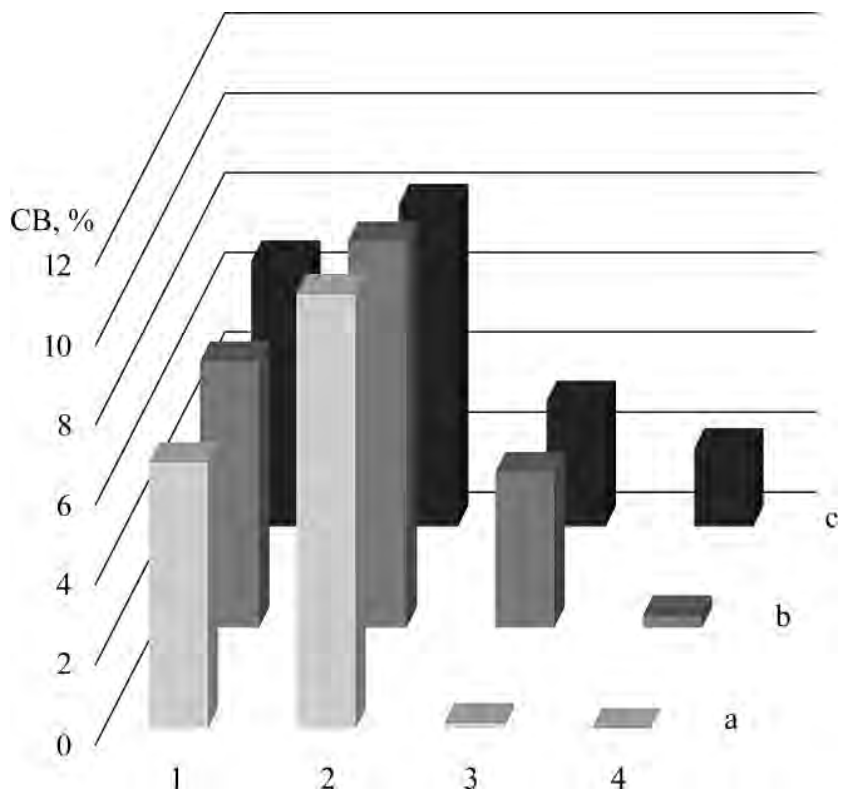

Рис. 3. Зависимость содержания сухих веществ молочной сыворотки от свежести: сыворотка свежая (а), ферментированная (b), переброженная (c); 1 - исходная сыворотка; 2 - концентрат; 3 - первый отгон; 4 - второй отгон.

зонах. Из-за избытка кислоты рН среды будет слабокислым в процессе электролиза и только резко увеличится в конце, указывая на окончание реакции и необходимость обновления сыворотки в катодной камере устройства.

В катодной камере электролизера в случае с подсгущенной ферментированной сывороткой дольше поддерживается слабокислая среда. Это оказывает положительное влияние на процесс накопления молочной кислоты [12].

В случае ферментированной сыворотки активная кислотность достигает оптимального значения в течение 30 минут процесса, если же сыворотка свежая, активная кислотность только после получаса соответствует нейтральной среде.

Для получения чистых растворов кислот был разработан аппарат с периодической дистилляцией в вакууме, практически свободном от кислорода. Технический результат - прямая экстракция уксусной кислоты. В процессе испарения имеются три фазы кипения сыворотки, что позволяет разделить компоненты обработанной, переброженной сыворотки. В случае со свежей сывороткой кипение наблюдается значительно позднее.

При использовании фракционной перегонки (начальное содержание сухих веществ в кислой 
сыворотке около 7\%) наблюдается следующее разделение сухих веществ: в объем первого отгона попадает около 4\%, второго - до $1 \%$. В сыворотке концентрируется до 9\% сухих веществ. В первом отгоне наиболее легкокипящие фракции - ацетальдегид и уксусная кислота. Отгон кислый (pH-3,6), концентрация сухих веществ - до 4\%. При вакууме происходят вспенивание и выброс фракции в отгон.

Выброс происходит и при нагревании паров альдегида и воздуха [13]. Процесс сгущения зависит от кислотности сыворотки [14]. В случае кислой сыворотки наблюдается быстрое вскипание (наличие углекислого газа, ацетальдегида, температура кипения которого $20^{\circ} \mathrm{C}$ ), при этом происходит активная конденсация пара в аппарате.

В первом отгоне содержится до 4\% уксусной кислоты и 1\% - во втором. Тем самым фракционированием выделено из молочной сыворотки до $5 \%$ уксусной кислоты. Первоначально закипает ацетальдегид, его температура кипения в предвакуумном состоянии понижается, после подключения нагревания начинается процесс его отгона. Но ацетальдегид - промежуточный продукт, для получения альдегида оптимально $\mathrm{pH}-2-5$, что характерно для первого случая.

В сыворотке, поступающей сразу после технологической операции, картина совсем иная. В составе первой фракции отгона свежей сыворотки ( $\mathrm{pH}-5)$ содержатся лишь летучие вещества, это летучие жирные кислоты уксусная, муравьиная, пропионовая, масляная. Процесс концентрирования требует постепенного нагрева, так как может происходить быстрое вскипание летучей фракции. Температура начала конденсации составляет $55^{\circ} \mathrm{C}$. Отгон также кислый $(\mathrm{pH}-3,6)$, сухих веществ не содержит. Сыворотку концентрировали до 10,9\% сухих веществ (рис. 3).

Если растворы уксусной кислоты перегонять при разных давлениях, разность между содержанием уксусной кислоты в жидкости и в парах изменяется - при повышении давления понижается [14]. Давление при перегонке свежей сыворотки изменялось от 6 до 12 кПа. Результаты приведены в табл. 1 и 2.

\section{ВЫВОДЫ}

При сгущении молочной сыворотки сохраняются полностью все ее компоненты, значительно снижаются расходы на транспортировку, повышаются сроки ее хранения. С точки зрения сохранения нативных свойств компонентов молочной сыворотки при еe сгущении необходимо поддерживать более низкие температуры. Исходя из термической устойчивости компонентов молочной сыворотки, максимальной температурой сгущения является $50-60^{\circ} \mathrm{C}$.

Для снижения потребления энергии сыворотку можно считать пастеризованной до конца конденсации в вакуумном испарителе. Фракционированием была отделена из молочной сыворотки вся уксусная кислота (до 5\%), содержащаяся до тепловой обработки. При получении уксуса необходимо контролировать температуру во избежание заметной потери спирта и уксусной кислоты вследствие их полного окисления до $\mathrm{CO}_{2}$ и $\mathrm{H}_{2} \mathrm{O}$.

Результаты показывают реальность производства кислоты из вторичного сырья: уксусной - из сильно сброженной сыворотки. При удалении уксусного альдегида и уксусной кислоты из исходного сырья фракционной перегонкой улучшается состав оставшейся фракции молочной сыворотки, что способствует ее дальнейшей переработке и получению молочной кислоты и других органических соединений.

\section{ЛИТЕРАТУРА}

1. Храмцов, А.Г., Инновационные разработки в использовании молочной сыворотки. Техника $u$ технология пищевых производств, 2018, т. 48, № 3, c. 5. doi: https://doi.org/10.21603/2074-94142018-3-5-15.

2. Бузоверов, С.Ю., Сурай, Н.М., Исследование влияния процесса сгущения подсырной сыворотки на выход готовой продукции. Вестник Алтайского государственного аграрного университета, 2016, т. 139 , № 5, c. 157.

3. Славоросова, Е.В., Куленко, В.Г., Шевчук, В.Б., Фиалкова, Е.А., Кристаллизатор-выпариватель для переработки молочной сыворотки. Молочнохозяйственный вестник, 2016, т. 23, № 3, с. 76.

4. Косенко, М.Е., Куликова, И.К., Донских, А.Н., Анисимов, Г.С. и др. Исследование влияния массовой доли сухих веществ на развитие микрофлоры творожной сыворотки в процессе электродиализной обработки. Техника $u$ технология пищевых производств, 2016, т. 41, № 2, c. 40.

5. Тимкин, В.А., Лазарев, В.А., Производство концентрата молочной сыворотки баромембранными методами. Переработка молока, 2014, № 5 , c. 32 .

6. Храмцов, А.Г., Интенсивная технология молочного сахара. М.: ДеЛи принт, 2004, 277 с.

7. Куличенко, А.И., Применение продуктов из молочной сыворотки при производстве кондитерских изделий. Молодой ученый, 2013, № 4, c. 675. https://moluch.ru/archive/51/6511/

8. Маньков, А.В., Минухин, Л.А., Концентрирование технологических пищевых растворов в выпарных установках с тепловым насосом. Аграрный вестник Урала, 2018, т. 170, № 03, с. 55. 
9. Ермолаев, В.А., Иваненко, О.Н., Онюшев, М.В., Разработка температурных режимов вакуумного концентрирования молока. Вестник КрасГАУ, 2016, № 9, с. 121.

10. Стефанкин, А.Е., Исследование конструктивных и технологических параметров мембранного аппарата при концентрировании творожной сыворотки. Техника и технология пищевых производств, 2016, т. 42, № 3, с. 133.

11. Кудряшов, В.Л., Производство кормовых добавок из молочной сыворотки на основе инновационных мембранных и биотехнологических процессов. Пищеевая индустрия, 2018, т. 37, № 3, с. 53.

12. Самуйленко, А.Я., Гринь, С.А., Еремец, В.И., Шинкарев, С.М. и др. Тенденции развития производства молочной кислоты. Вестник Казанского технологического университета, 2017, $\begin{array}{lllll}\text { т. } 20, \quad № & 1, & \text { c. } & 162 .\end{array}$ https://cyberleninka.ru/article/n/tendentsii-razvitiyaproizvodstva-molochnoy-kisloty

13. Просеков, А.Ю., Ермолаев, В.А., Подбор остаточного давления для вакуумного концентрирования жидких молочных продуктов. Достижения науки и техники АПК, 2010, № 6, c. 69 .
14. Ермолаев, В.А., Комарова, Н.А., Курбанова, М.Г., Интенсификация процесса вакуумного обезвоживания молочно-белковых продуктов. Хранение и переработка сельхозсырья, 2012, № 2, c. 8 .

\section{Summary}

The research considers main approaches to the problem of the milk industry by-products processing, in particular, of whey generated in great volumes during curd and cheese producing. The article examines the process of extracting an organic matter from whey by the fractionation of whey via distillation under low vacuum. It is advisable to process concentrated whey. Treatment of whey using fractional distillation under vacuum allows obtaining organic acids of the required purity and the required concentration. The article considers the direction that makes it possible to obtain cost-effective whey processing method, combining the concentration of whey by fractional distillation with its lectrical processing. This process allows to separate the organic matter of whey and to direct the process of further concentration of the resulting preparations towards the formation of certain organic compounds.

Keywords: whey, organic acids, fractional distillation, electrical processing 